6:43PM DEC 01,2022

THE MOMENT YOUR GUT INSTINCT

WAS BACKED BY SCIENTIFIC

RESULTS

\title{
THE DIFFERENCE OF
}

\section{BREAKTHROUGH MOMENTS}

\section{WITH COMPLETE SOLUTIONS FOR GROUNDBREAKING DISCOVERIES FROM A TRUSTED PARTNER.}

Your next breakthrough could be closer than you imagine, especially with the right resources to help you advance your research. At BD, we are dedicated to helping you get the data you need, when, where and how you need it. Our integrated solutions in instrumentation, software and reagents are optimized to work together to bring you closer to your next breakthrough moment. And you can depend on us for world-class training, service and support to help you get the most from the results your research depends on. Discover a range of optimized solutions that open endless possibilities for your future research. Discover the new BD. 


\section{Meat intake and risk of gastric cancer in the Stomach cancer Pooling (StoP) Project}

Ana Ferro ${ }^{1}$, Valentina Rosato ${ }^{3}$, Matteo Rota ${ }^{4,5}$, Ana Rute Costa $^{1}$, Samantha Morais ${ }^{1}$, Claudio Pelucchi $^{4}$, Kenneth C. Johnson ${ }^{6}$, Jinfu Hu ${ }^{7}$, Domenico Palli ${ }^{8}$, Monica Ferraroni ${ }^{4}$, Zuo-Feng Zhang ${ }^{9}$, Rossella Bonzi ${ }^{4}$, Guo-Pei Yu ${ }^{10}$, Bárbara Peleteiro ${ }^{1,2}$, Lizbeth López-Carrillo ${ }^{11}$, Shoichiro Tsugane ${ }^{12}$, Gerson Shigueaki Hamada ${ }^{13}$, Akihisa Hidaka ${ }^{12}$, David Zaridze ${ }^{14}$, Dmitry Maximovitch ${ }^{14}$, Jesus Vioque ${ }^{15,16}$, Eva M. Navarrete-Munoz ${ }^{15,16}$, Nuria Aragonés ${ }^{15,17}$, Vicente Martín ${ }^{15,18}$, Raúl Ulises Hernández-Ramírez ${ }^{11,19}$, Paola Bertuccio ${ }^{4,20}$, Mary H. Ward ${ }^{21}$, Reza Malekzadeh ${ }^{22}$, Farhad Pourfarzi ${ }^{22,23}$, Lina $\mathrm{Mu}^{24}$, Malaquias Lópes-Cervantes ${ }^{25}$, Roberto Persiani ${ }^{26,27}$, Robert C. Kurtz ${ }^{28}$, Areti Lagiou ${ }^{29}$, Pagona Lagiou ${ }^{30,31}$, Paolo Boffetta ${ }^{32,33}$, Stefania Boccia ${ }^{34,35}$, Eva Negri ${ }^{20}, \mathrm{M}$. Constanza Camargo ${ }^{21}$, Maria Paula Curado ${ }^{36}$, Carlo La Vecchia ${ }^{4}$, Nuno Lunet ${ }^{1,2, *}$

${ }^{1}$ EPIUnit - Instituto de Saúde Pública da Universidade do Porto, Porto, Portugal

${ }^{2}$ Departamento de Ciências da Saúde Pública e Forenses e Educação Médica, Faculdade de Medicina da Universidade do Porto, Porto, Portugal

${ }^{3}$ Unit of Medical Statistics, Biometry and Bioinformatics, National Cancer Institute, IRCCS Foundation, Milan, Italy

${ }^{4}$ Department of Clinical Sciences and Community Health, Università degli Studi di Milano, 20133, Milan, Italy

${ }^{5}$ Department of Molecular and Translational Medicine, University of Brescia, Brescia, Italy

This article has been accepted for publication and undergone full peer review but has not been through the copyediting, typesetting, pagination and proofreading process which may lead to differences between this version and the Version of Record. Please cite this article as doi: $10.1002 / \mathrm{ijc} .32707$ 
${ }^{6}$ School of Epidemiology and Public Health, Department of Medicine, University of Ottawa, Ottawa, ON, Canada

${ }^{7}$ Harbin Medical University, Harbin, China

${ }^{8}$ Cancer Risk Factors and Life-Style Epidemiology Unit, Institute for Cancer Research, Prevention and Clinical Network - ISPRO, Florence, Italy

${ }^{9}$ Department of Epidemiology, UCLA Fielding School of Public Health and Jonsson, Comprehensive Cancer Center, Los Angeles, USA

${ }^{10}$ Medical Informatics Center, Peking University, Peking, China

${ }^{11}$ Mexico National Institute of Public Health, Morelos, Mexico

${ }^{12}$ Epidemiology and Prevention Group, Center for Public Health Sciences, National Cancer Center, Tokyo, Japan

${ }^{13}$ Nikkei Disease Prevention Center, São Paulo, Brazil

${ }^{14}$ Department of Epidemiology and Prevention, Russian N.N. Blokhin Cancer Research Center, Moscow, Russia

${ }^{15}$ Consortium for Biomedical Research in Epidemiology and Public Health (CIBERESP), Madrid, Spain

${ }^{16}$ Department of Public Health, Miguel Hernandez University, FISABIO-ISABIAL, Alicante, Spain

${ }^{17}$ Epidemiology Section, Public Health Division, Department of Health of Madrid, Madrid, Spain

${ }^{18}$ Research Group in Gene-Environment Interactions and Health, University of León, León, Spain 
${ }^{19}$ Department of Biostatistics, Yale School of Public Health, Yale School of Medicine, New Haven, CT, USA

${ }^{20}$ Department of Biomedical and Clinical Sciences, Università degli Studi di Milano, Milan, Italy

${ }^{21}$ Occupational and Environmental Epidemiology Branch, Division of Cancer Epidemiology and Genetics, National Cancer Institute, Rockville, MD, USA

${ }^{22}$ Digestive Oncology Research Center, Digestive Disease Research Institute, Tehran University of Medical Sciences, Tehran, Iran

${ }^{23}$ Digestive Disease Research Center, Ardabil University of Medical Sciences, Ardabil, Iran

${ }^{24}$ Department of Epidemiology and Environmental Health, School of Public Health and Health Professions, University at Buffalo, Buffalo, NY, USA

${ }^{25}$ Facultad de Medicina, UNAM. Coyoacán, 04510, Mexico.

${ }^{26}$ Fondazione Policlinico Universitario Agostino Gemelli IRCCS, Dipartimento Scienze Gastroenterologiche, Endocrino-Metaboliche e Nefro-Urologiche, Roma, Italia

${ }^{27}$ Università Cattolica del Sacro Cuore, Dipartimento di Chirurgia, Roma, Italia

${ }^{28}$ Department of Medicine, Memorial Sloan Kettering Cancer Centre, New York, NY, USA

${ }^{29}$ Department of Public and Community Health, School of Health Sciences, University of West Attica, Egaleo, Greece

${ }^{30}$ Department of Hygiene, Epidemiology and Medical Statistics, School of Medicine, National and Kapodistrian University of Athens, Athens, Greece 
${ }^{31}$ Department of Epidemiology, Harvard T.H. Chan School of Public Health, Boston, MA, USA

${ }^{32}$ The Tisch Cancer Institute, Icahn School of Medicine at Mount Sinai, New York, NY, USA

${ }^{33}$ Department of Medical and Surgical Sciences, University of Bologna, Bologna, Italy

${ }^{34}$ Fondazione Policlinico Universitario Agostino Gemelli IRCCS, Roma, Italia

${ }^{35}$ Università Cattolica del Sacro Cuore, Sezione di Igiene, Istituto di Sanità Pubblica, Roma, Italia

${ }^{36}$ Centro Internacional de Pesquisa, A. C. Camargo Cancer Center, São Paulo, Brasil 
Corresponding author: Nuno Lunet

Departamento de Ciências da Saúde Pública e Forenses e Educação Médica, Faculdade de Medicina, Universidade do Porto;

Alameda Prof. Hernâni Monteiro, 4200-319 Porto, Portugal

Tel: +351 913650130; fax: +351 225095618;

e-mail: nlunet@med.up.pt

\section{Abbreviations}

$\mathrm{BMI}$ - Body mass index; $\mathrm{Cl}$ - Confidence Interval; DTA - Data transfer agreement; FFQ - Food frequency questionnaire; OR - Odds Ratio; RR - Relative risk; StoP - Stomach cancer Pooling Project; WCRF - World Cancer Research Fund.

No conflict of interests to disclose.

This article is protected by copyright. All rights reserved. 


\section{Abstract}

The consumption of processed meat has been associated with non-cardia gastric cancer, but evidence regarding a possible role of red meat is more limited. This study aims to quantify the association between meat consumption, namely white, red and processed meat, and the risk of gastric cancer, through individual participant data meta-analysis of studies participating in the 'Stomach cancer Pooling (StoP) Project'.

Data from 22 studies, including 11,443 cases and 28,029 controls, were used. Study-specific odds ratios (ORs) were pooled through a two-stage approach based on random-effects models. An exposure-response relationship was modelled, using one and two-order fractional polynomials, to evaluate the possible non-linear association between meat intake and gastric cancer.

An increased risk of gastric cancer was observed for the consumption of all types of meat (highest vs. lowest tertile), which was statistically significant for red (OR: $1.24 ; 95 \% \mathrm{Cl}: 1.00-1.53$ ), processed (OR: 1.23; 95\%Cl: $1.06-1.43$ ) and total meat (OR: 1.30; 95\% Cl: 1.09-1.55). Exposureresponse analyses showed an increasing risk of gastric cancer with increasing consumption of both processed and red meat, with the highest OR being observed for an intake of $150 \mathrm{~g} /$ day of red meat (OR: $1.85 ; 95 \% \mathrm{Cl}: 1.56-2.20)$.

This work provides robust evidence on the relation between the consumption of different types of meat and gastric cancer. Adherence to dietary recommendations to reduce meat consumption may contribute to a reduction in the burden of gastric cancer. 
This article is protected by copyright. All rights reserved. 


\section{Introduction}

Gastric cancer incidence has long been falling and is expected to decline in the next years. ${ }^{1}$ Nevertheless, mortality rates remain high, placing gastric cancer as the third cause of oncological death worldwide. ${ }^{2}$

Dietary patterns have been associated with the risk of gastric cancer, ${ }^{3}$ but the role of specific food groups is generally less clear. ${ }^{4}$ Meat can be an important part of a balanced diet since it provides essential nutrients, such as proteins, amino acids, vitamins and other micronutrients. ${ }^{5,6}$ However, it can also represent a source of compounds, such as heterocyclic amines, polycyclic aromatic hydrocarbons, N-nitroso compounds and heme iron, which have the potential to increase the risk of cancer. ${ }^{7,8}$ In 2015, the International Agency for Research on Cancer classified processed meat (smoked and salted goods) as "carcinogenic to humans" and the "consumption of red meat" as "probably carcinogenic to humans" based essentially on data for colorectal cancer. ${ }^{9}$ More recently, the World Cancer Research Fund (WCRF) revised its Report on Diet, Nutrition, Physical Activity and Stomach Cancer, and concluded that there was suggestive evidence supporting a probable causal link between processed meat and non-cardia cancers, ${ }^{10}$ but for red meat no pooled analyses were available in that revision. ${ }^{10}$

The aim of this study is to quantify the association between meat consumption, namely white, red and processed meat, and the risk of gastric cancer, through individual participant data meta-analysis of studies participating in the 'Stomach cancer Pooling (StoP) Project'. 


\section{Material and Methods}

\section{Study population}

This study is based on the second release of the StoP Project dataset, which included 30 case-control studies, or case-control analyses nested within cohort studies, for a total of 14,016 cases of gastric cancer $(9,247$ men, 4,769 women) and 33,704 controls (20,352 men and 13,352 women). The StoP Project aims at examining the role of several lifestyles and genetic determinants in the etiology of gastric cancer through pooled analyses of individual-level data, after central collection and validation of the original data sets. For each study, a completion of a study description form providing information on the study characteristics was asked. Investigators who agreed to participate provided a signed DTA and, thereafter, the complete original data set; investigators not wishing to share the complete data set were invited to provide a set of core variables including, among others, age, sex, education/social class, smoking habits, family history of gastric cancer, selected variables, as well as markers of $H$. pylori infection, whenever available. In addition to the data sets, the original questionnaires and any useful information to help with data handling (codebooks, labels, etc.) was collected from the participating studies, to optimize data harmonization. All data were harmonized at the pooling center, according to a pre-specified format; the whole body of information was divided into several sections (e.g. sociodemographic characteristics, smoking habits, lifetime alcohol use, physical activity, etc.), and, for each topic, a project codebook was created reporting which variables were present in each study, their names and codes. The data for the core variables were standardized among studies, as well as for the variables for selected topics of interest. The StoP Project received ethical approval from the University of Milan Review Board (reference 
$19 / 15$ on $01 / 04 / 2015)$, and detailed information on the overall aims and methods has been given elsewhere. ${ }^{11}$

For the present analyses, individual-level data from 22 studies with information on meat intake was used, including 11,443 cases and 28,029 controls, from Brazil (two studies), ${ }^{12,}{ }^{13}$ Canada, ${ }^{14}$ China (two studies), ${ }^{15,}{ }^{16}$ Greece, ${ }^{17}$ Iran, ${ }^{18}$ Italy (four studies), ${ }^{19-22}$ Japan (three studies), ${ }^{23-25}$ Mexico (three studies), ${ }^{26-28}$ Portugal, ${ }^{29}$ Russia, ${ }^{30}$ Spain (two studies), ${ }^{31,32}$ and the USA. ${ }^{33}$

Variables defining the exposure

All studies assessed the participants' dietary habits through food frequency questionnaires (FFQ) focusing on diet in periods of one, two, three or five years before diagnosis (for cases), onset of disease or hospital admission (for hospital-based controls) or recruitment (for population-based controls). Twelve of the included studies reported that the questionnaire used was previously validated by comparison with multiple 24-hour recall interviews and/or diet records (Supplementary Table 1).These FFQs included between 15 and 147 individual food and beverage items frequently consumed in each country (Supplementary Table 1).

Food items identified as "chicken", "turkey" and "rabbit" were classified as white meat. Those identified as "beef", "pork", other non-poultry meat (e.g. "lamb"), as well as mammalian offals (such as "liver") were considered red meat. All meat items that had undergone some form of transformation (salting, curing, smoking, fermentation or other processes to enhance flavor or improve preservation) including those identified as "sausages", "bacon", "ham", "cold cuts", "croquettes" and "hot dogs" were classified as processed meat, regardless of including white or red meat. ${ }^{34}$ 


\section{Statistical analysis}

Study-specific frequency of consumption of each food item or group was converted into $\mathrm{g} /$ day, according to the information available in each questionnaire or country specific dietary standards (Brazilian ${ }^{35}$ studies), and categorized into tertiles on the basis of the study-specific distribution in the controls.

To quantify the associations between gastric cancer and white, red, processed, and total meat intake, both two- and one-stage modeling approaches were used. ${ }^{36}$

For the two-stage analysis, the association between meat intake and gastric cancer was first assessed by estimating the odds ratios (ORs) and the corresponding $95 \%$ confidence intervals (Cls) for each study, using multivariable unconditional logistic regression models. Considering that the proportion of missing data was low, a complete case approach was adopted. Models included, when available and applicable, terms for sex, age (5-year age groups: $<40 ; 40-44 ; \ldots ; 70-74 ; \geq 75$ ), socioeconomic status (low, intermediate, or high, as defined in each original study based on education, income or occupation), smoking status (never, former and current smokers of $\leq 10$ cigarettes/day; 11 to 20 cigarettes/day; $>20$ cigarettes/day), alcohol drinking (never, low: $\leq 12 \mathrm{~g}$ of ethanol/day, intermediate: $>12$ to $47 \mathrm{~g}$ of ethanol/day, high: $>47$ g of ethanol/day), fruits and vegetables consumption (study-specific tertiles), total energy intake (study-specific quintiles), study center (for multicenter studies), race/ethnicity ("White", "Black/African American", "Asian", "Hispanic/Latino", "Other"), body mass index (BMI) categories $\left(<18.5,18.5-25,25-30,>30 \mathrm{~kg} / \mathrm{m}^{2}\right)$ and family history of gastric cancer (Supplementary Table 2). Then, summary (pooled) effects estimates were computed as weighted averages of each study's ORs, using random-effects models. ${ }^{37}$ This was performed for 
the comparison between the second and third study-specific tertile, with the first as the reference category.

Heterogeneity between studies was tested using the $Q$ test statistics and quantified using $l^{2}$, i.e. the percentage of the total variation across studies that is due to heterogeneity rather than chance. ${ }^{38}$

Stratified analyses were carried out to investigate the effect of high consumption of each type of meat across strata of selected covariates, including sex, age, geographic area of the studies, socioeconomic status, smoking status, alcohol drinking, BMI categories, family history of gastric cancer, but also according to and type of controls (hospital-based, population-based), cancer anatomical location (cardia, non-cardia) and histological type (intestinal, diffuse and undifferentiated, as defined by the Lauren classification). For the analyses according to cancer subsite and histological type we used multinomial logistic regression models to estimate the ORs for each type of cancer separately (i.e., cardia and non-cardia or intestinal and diffuse). The difference between groups was assessed through the $Q$ test for heterogeneity. ${ }^{38}$ Sensitivity analyses were performed by excluding one study at a time, and by defining the same categories of exposure for all studies: initially using tertiles of the distribution of meat consumption in all controls as cut-offs to define the categories; then, since the maximum amounts of intake recommended by the WCRF are $300 \mathrm{~g} /$ week for red meat and $50 \mathrm{~g} /$ week for processed meat, using cut-offs that describe intakes of less than half of the recommended intake, between half and the recommended amount, or more than the recommended amount, resulting in three categories of exposure. Additionally, adjusted and unadjusted estimates for total energy intake, as well as for H. pylori infection status were compared, among studies with information on these variables. 
A one-stage strategy of analysis was used to assess the significance of a linear trend, by considering the variables defining meat intake as continuous, ${ }^{39}$ and to model the functional form of the relation between the daily amount (g) of meat consumed (continuous) and gastric cancer risk. The latter was accomplished through first- and second-order fractional polynomial models, including study center and the core variables used in the main analysis as covariates; this family of models includes the predefined set of power terms $P=\{-2 ;-1 ;-0.5 ; 0 ; 1 ; 0.5 ; 2 ; 3\}$, where $P=0$ means $\log (X)$ and the linear model has $P=1$. The best-nonlinear fitting model, i.e., the one minimizing the model difference with respect to the linear model, was selected. ${ }^{40}$

\section{Data availability}

The data that support the findings of this study are available from the Stomach cancer Pooling (StoP) Project but restrictions apply to the availability of these data, which were used under license for the current study, and so are not publicly available. Data are however available from the authors upon reasonable request and with permission of the Steering Committee of the StoP Project. 


\section{Results}

Tables 1 and 2 describe the main characteristics of the 11,443 cases and 28,029 controls considered for the present analysis. The median meat intake among controls ranged between 0.3 and $38.7 \mathrm{~g} /$ day for white meat, between 21.4 and $99.5 \mathrm{~g} /$ day for red meat and between 0.0 and $26.9 \mathrm{~g} /$ day for processed meat; gastric cancer cases generally presented higher levels of consumption, particularly for red meat and among studies from the Americas (median intake: $61.3 \mathrm{~g} /$ day) (Table 1). Compared to controls, cases had higher proportions of men (65.1 vs $59.4 \%$ ) and individuals who were older (45.6 vs $39.8 \%$ over 65 years of age), with low socioeconomic status ( 50.4 vs $36.8 \%$ ), current smokers ( 29.9 vs $25.9 \%$ ) or alcohol drinkers $(59.2$ vs $51.9 \%)$ (Table 2 ).

Pooled ORs and corresponding $95 \% \mathrm{Cls}$ for the association between meat consumption and gastric cancer are presented in Table 3 and Figure 1 . The odds were significantly higher for the highest versus the lowest tertile of red (OR: $1.24 ; 95 \% \mathrm{Cl}: 1.00-1.53)$, processed (OR: 1.23 ; 95\% Cl: $1.06-1.43)$ and total meat intake (OR: $1.30 ; 95 \% \mathrm{Cl}: 1.09-1.55)$.

Table 4 presents the results from the stratified analyses. For most of the strata considered, there was an increased risk of gastric cancer with a high intake of all types of meat analyzed. The only significant difference across strata was observed for processed meat, regarding the geographic area of the studies; the strongest associations were observed among the American (OR: 1.45; 95\% Cl: 1.15-1.84) and the European studies (OR: 1.28; 95\% Cl: $1.02-$ 1.60), whereas in Asian studies there was no significant association (OR: 0.98; 95\% $\mathrm{Cl}: 0.80-1.20$ ).

When considering results adjusted for total energy intake, heterogeneity tended to be lower and the association remained significant for processed (OR: 1.16; $95 \% \mathrm{Cl}: 1.00-1.35$ ) and 
total meat intake (OR: $1.22 ; 95 \% \mathrm{Cl}: 1.06-1.41)$. Regarding adjustment for $\mathrm{H}$. pylori infection, it also contributed to lower heterogeneity, though no significant associations were observed. (Table 4). The main findings remained unchanged after further sensitivity analyses (Supplementary Tables 3 and 4 and Supplementary Figure 1), though heterogeneity decreased slightly when defining the same categories of exposure for all studies, either using the overall distribution in all controls (Supplementary Table 3) or the amounts recommended by the WCRF (Supplementary Table 4).

The dose-response relationships between the intake of red and processed and gastric cancer are depicted in Figure 2A and 2B, respectively. There is a trend towards increased gastric cancer risk with a higher consumption of red and processed meat, with an OR of 1.85 (95\% Cl: 1.56-2.20) for the consumption of $150 \mathrm{~g} /$ day of red meat, and an OR of 1.38 (95\% Cl: $1.28-1.49)$ for the consumption of $50 \mathrm{~g} /$ day of processed meat. 


\section{Discussion}

This study was based on an individual participant data approach, which constitutes the gold standard in evidence synthesis, allowing us to better quantify than previously available reports an increased risk of gastric cancer with high intakes of meat, particularly red and processed meat. This was further confirmed through the computation and graphical depiction of the exposure-response association.

Previous studies have shown positive and significant associations between high intakes of red and processed meat and gastric cancer. Compared to meta-analyses of cohort studies, our estimates are higher (Zhu et al.., ${ }^{41}$ relative risk [RR] for the highest vs lowest intake of red meat 1.05 [95\% Cl: 0.87-1.27]; Song et al., ${ }^{42}$ RR for the highest vs lowest intake of red meat 1.00 [95\% Cl: 0.82-1.20]; Zhao et al., ${ }^{43} \mathrm{RR}$ for the highest vs lowest intake of red meat 1.14 [95\% Cl: 0.97-1.34] and RR for the highest vs lowest intake of processed meat 1.23 [95\% Cl: 0.98-1.55]; Kim et al, ${ }^{44} \mathrm{RR}$ for the highest vs lowest intake of red meat 1.03 [95\% Cl: 0.83-1.28] and RR for the highest vs lowest intake of processed meat 1.24 [95\% Cl: 1.04-1.47]). Nevertheless, the estimates obtained in this study are of lower magnitude than those from the previous metaanalyses of case-control studies: Zhu et al ${ }^{41}$ found RR estimates of 1.63 (95\% Cl: 1.33-1.99) for red meat and 1.64 (95\% Cl: $1.47-1.83)$ for processed meat from a total of 13 and 18 case-control studies, respectively; Song et $a l^{42}$ had a relative risk estimate of 1.59 (95\% Cl:1.34-1.89) for red meat with 18 studies; Zhao et $a l^{43}$, with 20 case-control studies for red meat and 25 for processed meat, obtained even higher estimates (red meat: 1.67 [95\% Cl: 1.36-2.05]; processed meat: 1.76 [95\% Cl: 1.51-2.05] and, most recently, Kim et al, ${ }^{44}$ with 20 case-control studies for red meat and 23 for processed meat obtained estimates similar to those from Zhao et al (red 
meat: 1.57 [95\% Cl: $1.30-1.89]$; processed meat: 1.79 [95\% Cl: 1.51-2.12]). We have previously observed that, both smoking and alcohol drinking, the estimates obtained from the StoP Project were lower than the ones found in previous meta-analyses of case-control studies, ${ }^{45,46}$ which is likely a reflection of the methodological strengths of individual participant data pooled analyses in terms of a more uniform strategy of analysis across studies, including control of confounding and reduction of publication bias.

The higher concentration of carcinogenic compounds such as heme iron ${ }^{47}$ and $\mathrm{N}$-nitroso compounds ${ }^{8}$ present in red and processed meat contributes to explain the higher OR estimates obtained for these food groups compared with those for white meat. Furthermore, the type of processing determines the degree of carcinogenicity, ${ }^{48}$ with smoking and grilling of meats resulting in the formation of more polycyclic aromatic hydrocarbons, heterocyclic amines and other carcinogens. ${ }^{49}$ An additional hypothesis was bacterial plasmids (DNA) from meat, namely from dairy cattle, which may contribute to chronic inflammation and, in the long term, promote carcinogenesis. ${ }^{50}$

Regional differences, in particular higher estimates for American and European countries, were observed. Though previous meta-analyses have shown an increased risk of gastric cancer for higher consumptions of meat regardless of the geographic region, Asian studies tend to present the lowest estimates. ${ }^{41,42,44}$ The different dietary patterns between geographical regions, which determine the exposure to different amounts and types of meat, can help explain the geographic differences; as well as methodological issues of the studies included in previous meta-analyses, namely regarding control of confounding. In our study, Asian studies are those that present, for all types of meat considered, lower median values of 
consumption, which may contribute to the lower estimate obtained compared with the other studies where consumption is higher. Also, the variability in the detail, definition and assessment of dietary exposures across countries also contributes to the regional differences and to the high heterogeneity observed for all estimates in the present study, as well as in other investigations on dietary factors. ${ }^{51}$ Although most studies within the StoP Project used validated FFQs, and the methods used to obtain dietary information and some of the dietary items included in the questionnaires were similar among studies, there are considerable differences concerning the dietary patterns within each study. Nevertheless, stratified and sensitivity analyses did not result in significant changes in cancer risk estimates for all types of meat considered. However, we observed slight lower heterogeneity particularly when adjusting for total energy intake and when considering the same cut-offs for all studies.

This work adds to previous evidence by providing pooled OR estimates for different types of meat, including the characterization of the exposure-response relationships. Our results provide additional evidence that adherence to the dietary recommendations to reduce meat consumption, as those from the WCRF, is likely to contribute to a reduction in the burden of gastric cancer. 


\section{Acknowledgments:}

This study was supported by the Associazione Italiana per la Ricerca sul Cancro (AIRC), Project no. 21378 (Investigator Grant), by the Italian Ministry of Health (Young Researchers, GR-201102347943 to SB), by the Italian League for the Fight Against Cancer (LILT) and by the Associazione Industriale delle Carni e dei Salumi (ASSICA, to the Department of Clinical Sciences and Community Health, University of Milan).

This study was also funded by FEDER through the Operational Programme Competitiveness and Internationalization and national funding from the Foundation for Science and Technology - FCT (Portuguese Ministry of Science, Technology and Higher Education) under the Unidade de Investigação em Epidemiologia - Instituto de Saúde Pública da Universidade do Porto (EPIUnit) (POCI-01-0145-FEDER-006862; Ref. UID/DTP/04750/2013). AF (PD/BD/105823/2014) was awarded with an individual scholarship through national funding from FCT/MCTES. Individual grants attributed to ARC (SFRH/BD/102181/2014), and BP (SFRH/BPD/108751/2015) were funded by the FCT and the "Programa Operacional Capital Humano" (POCH/FSE). SM was funded under the project "NEON-PC - Neuro-oncological complications of prostate cancer: longitudinal study of cognitive decline " (POCI-01-0145-FEDER-032358; Ref. PTDC/SAU-EPI/32358/2017).

Valentina Rosato was supported by a fellowship by the Italian Foundation for Cancer Research (FIRC \#18104).

The authors thank the European Cancer Prevention (ECP) Organization for providing support for the StoP meetings. 
We also thank all MCC-Spain study collaborators (CIBERESP, ISCIII, ISGlobal, ICO, University of Huelva, University of Oviedo, University of Cantabria, University of León, ibs. Granada, Instituto Salud Pública de Navarra, FISABIO, Murcia Regional Health Authority and cols) 


\section{References}

1. Ferro A, Peleteiro B, Malvezzi M, Bosetti C, Bertuccio P, Levi F, Negri E, La Vecchia C, Lunet N. Worldwide trends in gastric cancer mortality (1980-2011), with predictions to 2015, and incidence by subtype. Eur J Cancer 2014;50: 1330-44.

2. Bray F, Ferlay J, Soerjomataram I, Siegel RL, Torre LA, Jemal A. Global cancer statistics 2018: GLOBOCAN estimates of incidence and mortality worldwide for 36 cancers in 185 countries. CA Cancer J Clin 2018;68: 394-424.

3. Bertuccio P, Rosato V, Andreano A, Ferraroni M, Decarli A, Edefonti V, La Vecchia C. Dietary patterns and gastric cancer risk: a systematic review and meta-analysis. Ann Oncol 2013;24: 1450-8.

4. Fang X, Wei J, He X, An P, Wang H, Jiang L, Shao D, Liang H, Li Y, Wang F, Min J. Landscape of dietary factors associated with risk of gastric cancer: A systematic review and doseresponse meta-analysis of prospective cohort studies. Eur J Cancer 2015;51: 2820-32.

5. De Smet S, Vossen E. Meat: The balance between nutrition and health. A review. Meat Sci 2016;120: 145-56.

6. Lippi G, Mattiuzzi C, Cervellin G. Meat consumption and cancer risk: a critical review of published meta-analyses. Crit Rev Oncol Hematol 2016;97: 1-14.

7. Ward MH, Cross AJ, Abnet CC, Sinha R, Markin RS, Weisenburger DD. Heme iron from meat and risk of adenocarcinoma of the esophagus and stomach. Eur J Cancer Prev 2012;21: 134-8.

8. Van Hecke T, Vossen E, Hemeryck LY, Vanden Bussche J, Vanhaecke L, De Smet S. Increased oxidative and nitrosative reactions during digestion could contribute to the association between well-done red meat consumption and colorectal cancer. Food Chem 2015;187: 29-36.

9. Bouvard V, Loomis D, Guyton KZ, Grosse Y, Ghissassi FE, Benbrahim-Tallaa L, Guha N, Mattock H, Straif K, International Agency for Research on Cancer Monograph Working G. Carcinogenicity of consumption of red and processed meat. Lancet Oncol 2015;16: 1599-600.

10. World Cancer Research Fund International/American Institute for Cancer Research, Continuous Update Project Report: Diet, Nutrition, Physical Activity and Stomach Cancer., 2016; Available from: wcrf.org/stomach-cancer-2016. 
11. Pelucchi C, Lunet N, Boccia S, Zhang ZF, Praud D, Boffetta P, Levi F, Matsuo K, Ito H, Hu J, Johnson KC, Ferraroni M, Yu GP, Peleteiro B, Malekzadeh R, Derakhshan MH, Ye W, Zaridze D, Maximovitch D, Aragones N, Martin V, Pakseresht M, Pourfarzi F, Bellavia A, Orsini N, Wolk A, Mu L, Arzani D, Kurtz RC, Lagiou P, Trichopoulos D, Muscat J, La Vecchia C, Negri E. The stomach cancer pooling (StoP) project: study design and presentation. Eur J Cancer Prev 2015;24: 16-23.

12. Hamada GS, Kowalski LP, Nishimoto IN, Rodrigues JJ, Iriya K, Sasazuki S, Hanaoka T, Tsugane S, Sao Paulo--Japan Cancer Project Gastric Cancer Study G. Risk factors for stomach cancer in Brazil (II): a case-control study among Japanese Brazilians in Sao Paulo. Jpn J Clin Oncol 2002;32: 284-90.

13. Nishimoto IN, Hamada GS, Kowalski LP, Rodrigues JG, Iriya K, Sasazuki S, Hanaoka T, Tsugane S, Sao Paulo--Japan Cancer Project Gastric Cancer Study G. Risk factors for stomach cancer in Brazil (I): a case-control study among non-Japanese Brazilians in Sao Paulo. Jpn J Clin Oncol 2002;32: 277-83.

14. Mao Y, Hu J, Semenciw R, White K, Canadian Cancer Registries Epidemiology Research G. Active and passive smoking and the risk of stomach cancer, by subsite, in Canada. Eur J Cancer Prev 2002;11: 27-38.

15. Mu LN, Lu QY, Yu SZ, Jiang QW, Cao W, You NC, Setiawan VW, Zhou XF, Ding BG, Wang RH, Zhao J, Cai L, Rao JY, Heber D, Zhang ZF. Green tea drinking and multigenetic index on the risk of stomach cancer in a Chinese population. Int J Cancer 2005;116: 972-83.

16. Setiawan VW, Yu GP, Lu QY, Lu ML, Yu SZ, Mu L, Zhang JG, Kurtz RC, Cai L, Hsieh CC, Zhang ZF. Allium vegetables and stomach cancer risk in China. Asian Pac J Cancer Prev 2005;6: 387-95.

17. Lagiou P, Samoli E, Lagiou A, Peterson J, Tzonou A, Dwyer J, Trichopoulos D. Flavonoids, vitamin C and adenocarcinoma of the stomach. Cancer Causes Control 2004;15: 6772.

18. Pourfarzi F, Whelan A, Kaldor J, Malekzadeh R. The role of diet and other environmental factors in the causation of gastric cancer in Iran--a population based study. Int $J$ Cancer 2009;125: 1953-60. 
19. La Vecchia C, D'Avanzo B, Negri E, Decarli A, Benichou J. Attributable risks for stomach cancer in northern Italy. Int J Cancer 1995;60: 748-52.

20. Lucenteforte E, Scita V, Bosetti C, Bertuccio P, Negri E, La Vecchia C. Food groups and alcoholic beverages and the risk of stomach cancer: a case-control study in Italy. Nutr Cancer 2008;60: 577-84.

21. De Feo E, Simone B, Persiani R, Cananzi F, Biondi A, Arzani D, Amore R, D'Ugo D, Ricciardi G, Boccia S. A case-control study on the effect of Apolipoprotein E genotypes on gastric cancer risk and progression. BMC Cancer 2012;12: 494.

22. Buiatti E, Palli D, Decarli A, Amadori D, Avellini C, Bianchi S, Biserni R, Cipriani F, Cocco P, Giacosa A, et al. A case-control study of gastric cancer and diet in Italy. Int J Cancer 1989;44: 611-6.

23. Machida-Montani A, Sasazuki S, Inoue M, Natsukawa S, Shaura K, Koizumi Y, Kasuga $\mathrm{Y}$, Hanaoka T, Tsugane S. Association of Helicobacter pylori infection and environmental factors in non-cardia gastric cancer in Japan. Gastric Cancer 2004;7: 46-53.

24. Matsuo K, Oze I, Hosono S, Ito H, Watanabe M, Ishioka K, Ito S, Tajika M, Yatabe Y, Niwa Y, Yamao K, Nakamura S, Tajima K, Tanaka H. The aldehyde dehydrogenase 2 (ALDH2) Glu504Lys polymorphism interacts with alcohol drinking in the risk of stomach cancer. Carcinogenesis 2013;34: 1510-5.

25. Inoue M, Tajima K, Hirose K, Hamajima N, Takezaki T, Kuroishi T, Tominaga S. Epidemiological features of first-visit outpatients in Japan: comparison with general population and variation by sex, age, and season. J Clin Epidemiol 1997;50: 69-77.

26. Hernandez-Ramirez RU, Galvan-Portillo MV, Ward MH, Agudo A, Gonzalez CA, Onate-Ocana LF, Herrera-Goepfert R, Palma-Coca O, Lopez-Carrillo L. Dietary intake of polyphenols, nitrate and nitrite and gastric cancer risk in Mexico City. Int J Cancer 2009;125: 1424-30.

27. Lopez-Carrillo L, Lopez-Cervantes M, Robles-Diaz G, Ramirez-Espitia A, MoharBetancourt A, Meneses-Garcia A, Lopez-Vidal Y, Blair A. Capsaicin consumption, Helicobacter pylori positivity and gastric cancer in Mexico. Int J Cancer 2003;106: 277-82.

28. Lopez-Carrillo L, Hernandez Avila M, Dubrow R. Chili pepper consumption and gastric cancer in Mexico: a case-control study. Am J Epidemiol 1994;139: 263-71. 
29. Lunet N, Valbuena C, Vieira AL, Lopes C, Lopes C, David L, Carneiro F, Barros H. Fruit and vegetable consumption and gastric cancer by location and histological type: case-control and meta-analysis. Eur J Cancer Prev 2007;16: 312-27.

30. Zaridze D, Borisova E, Maximovitch D, Chkhikvadze V. Alcohol consumption, smoking and risk of gastric cancer: case-control study from Moscow, Russia. Cancer Causes Control 2000;11: 363-71.

31. Castano-Vinyals G, Aragones N, Perez-Gomez B, Martin V, Llorca J, Moreno V, Altzibar JM, Ardanaz E, de Sanjose S, Jimenez-Moleon JJ, Tardon A, Alguacil J, Peiro R, MarcosGragera R, Navarro C, Pollan M, Kogevinas M, Group MC-SS. Population-based multicase-control study in common tumors in Spain (MCC-Spain): rationale and study design. Gac Sanit 2015;29: 308-15.

32. Santibanez M, Alguacil J, de la Hera MG, Navarrete-Munoz EM, Llorca J, Aragones N, Kauppinen T, Vioque J, Group PS. Occupational exposures and risk of stomach cancer by histological type. Occup Environ Med 2012;69: 268-75.

33. Zhang ZF, Kurtz RC, Klimstra DS, Yu GP, Sun M, Harlap S, Marshall JR. Helicobacter pylori infection on the risk of stomach cancer and chronic atrophic gastritis. Cancer Detect Prev 1999;23: 357-67.

34. International Agency for Research on Cancer. IARC Monographs evaluate consumption of red meat and processed meat http://www.iarc.fr/en/mediacentre/pr/2015/pdfs/pr240 E.pdf, 2015.

35. Instituto Brasileiro de Geografia e Estatística - IBGE, Pesquisa de Orçamentos Familiares 2008-2009 Tabela de Medidas Referidas para os Alimentos Consumidos no Brasil,. Ministério do Planejamento, Orçamento e Gestão,, 2011; Available from: https://biblioteca.ibge.gov.br/visualizacao/livros/liv50000.pdf.

36. Burke DL, Ensor J, Riley RD. Meta-analysis using individual participant data: onestage and two-stage approaches, and why they may differ. Stat Med 2017;36: 855-75.

37. DerSimonian R, Laird N. Meta-analysis in clinical trials. Control Clin Trials 1986;7: 17788.

38. Higgins JP, Thompson SG, Deeks JJ, Altman DG. Measuring inconsistency in metaanalyses. BMJ 2003;327: 557-60. 
39. Smith-Warner SA, Spiegelman D, Ritz J, Albanes D, Beeson WL, Bernstein L, Berrino F, van den Brandt PA, Buring JE, Cho E, Colditz GA, Folsom AR, Freudenheim JL, Giovannucci E, Goldbohm RA, Graham S, Harnack L, Horn-Ross PL, Krogh V, Leitzmann MF, McCullough ML, Miller AB, Rodriguez C, Rohan TE, Schatzkin A, Shore R, Virtanen M, Willett WC, Wolk A, Zeleniuch-Jacquotte A, Zhang SM, Hunter DJ. Methods for pooling results of epidemiologic studies: the Pooling Project of Prospective Studies of Diet and Cancer. Am J Epidemiol 2006;163: 1053-64.

40. Royston $P$, Ambler $G$, Sauerbrei $W$. The use of fractional polynomials to model continuous risk variables in epidemiology. International journal of epidemiology 1999;28: 96474.

41. Zhu H, Yang X, Zhang C, Zhu C, Tao G, Zhao L, Tang S, Shu Z, Cai J, Dai S, Qin Q, Xu L, Cheng $\mathrm{H}$, Sun $\mathrm{X}$. Red and processed meat intake is associated with higher gastric cancer risk: a meta-analysis of epidemiological observational studies. PLoS One 2013;8: e70955.

42. Song $P$, Lu M, Yin $Q$, Wu L, Zhang D, Fu B, Wang B, Zhao Q. Red meat consumption and stomach cancer risk: a meta-analysis. J Cancer Res Clin Oncol 2014;140: 979-92.

43. Zhao Z, Yin Z, Zhao Q. Red and processed meat consumption and gastric cancer risk: a systematic review and meta-analysis. Oncotarget 2017;8: 30563-75.

44. Kim SR, Kim K, Lee SA, Kwon SO, Lee JK, Keum N, Park SM. Effect of Red, Processed, and White Meat Consumption on the Risk of Gastric Cancer: An Overall and Dose(-)Response Meta-Analysis. Nutrients 2019;11.

45. Praud D, Rota M, Pelucchi C, Bertuccio P, Rosso T, Galeone C, Zhang ZF, Matsuo K, Ito $\mathrm{H}, \mathrm{Hu}$ J, Johnson KC, Yu GP, Palli D, Ferraroni M, Muscat J, Lunet N, Peleteiro B, Malekzadeh R, Ye W, Song H, Zaridze D, Maximovitch D, Aragones N, Castano-Vinyals G, Vioque J, NavarreteMunoz EM, Pakseresht M, Pourfarzi F, Wolk A, Orsini N, Bellavia A, Hakansson N, Mu L, Pastorino R, Kurtz RC, Derakhshan MH, Lagiou A, Lagiou P, Boffetta P, Boccia S, Negri E, La Vecchia C. Cigarette smoking and gastric cancer in the Stomach Cancer Pooling (StoP) Project. Eur J Cancer Prev 2018;27: 124-33.

46. Rota M, Pelucchi C, Bertuccio P, Matsuo K, Zhang ZF, Ito H, Hu J, Johnson KC, Palli D, Ferraroni M, Yu GP, Muscat J, Lunet N, Peleteiro B, Ye W, Song H, Zaridze D, Maximovitch D, Guevara M, Fernandez-Villa T, Vioque J, Navarrete-Munoz EM, Wolk A, Orsini N, Bellavia A, 
Hakansson N, Mu L, Persiani R, Kurtz RC, Lagiou A, Lagiou P, Galeone C, Bonzi R, Boffetta P, Boccia S, Negri E, La Vecchia C. Alcohol consumption and gastric cancer risk-A pooled analysis within the StoP project consortium. Int J Cancer 2017;141: 1950-62.

47. Ward HA, Gayle A, Jakszyn P, Merritt M, Melin B, Freisling H, Weiderpass E, Tjonneland A, Olsen A, Dahm CC, Overvad K, Katzke V, Kuhn T, Boeing H, Trichopoulou A, Lagiou P, Kyrozis A, Palli D, Krogh V, Tumino R, Ricceri F, Mattiello A, Bueno-de-Mesquita B, Peeters PH, Quiros JR, Agudo A, Rodriguez-Barranco M, Larranaga N, Huerta JM, Barricarte A, Sonestedt E, Drake I, Sandstrom M, Travis RC, Ferrari P, Riboli E, Cross AJ. Meat and haem iron intake in relation to glioma in the European Prospective Investigation into Cancer and Nutrition study. Eur J Cancer Prev 2018;27: 379-83.

48. Chiang VS, Quek SY. The relationship of red meat with cancer: Effects of thermal processing and related physiological mechanisms. Crit Rev Food Sci Nutr 2017;57: 1153-73.

49. Demeyer D, Mertens B, De Smet S, Ulens M. Mechanisms Linking Colorectal Cancer to the Consumption of (Processed) Red Meat: A Review. Crit Rev Food Sci Nutr 2016;56: 274766.

50. Zur Hausen $\mathrm{H}$, Bund $\mathrm{T}$, de Villiers EM. Specific nutritional infections early in life as risk factors for human colon and breast cancers several decades later. Int J Cancer 2019;144: 1574-83.

51. Boeing H. Nutritional epidemiology: New perspectives for understanding the dietdisease relationship? Eur J Clin Nutr 2013;67: 424-9. 
Table 1. Median and interquartile range (grams per [g/] day) of white, red and processed meat intake, by case-control status and study.

NA - not available; P25-P75 - percentile 25- percentile 75; USA - United States of America; ${ }^{[1]}$ Only total meat available.

Table 2. Distribution of gastric cancer cases and controls according to sex, age and other selected covariates.

\footnotetext{
${ }^{1}$ No information for the study Japan $2 .{ }^{23}$ As defined in each original study based on education, income or occupation.

${ }^{2}$ No information for the studies Canada, ${ }^{14}$ China 3,16 Mexico 1,26 Mexico $2{ }^{28}$ and Mexico $3 .{ }^{27}$

${ }^{3}$ Defined according to study-specific tertiles.

${ }^{4}$ No information for the studies Canada, ${ }^{14}$ China 2, ${ }^{15}$ Russia, ${ }^{30}$ Iran 1, ${ }^{18}$ Japan 2, ${ }^{23}$ Brazil $1^{13}$ and Brazil 2. ${ }^{12}$

${ }^{5}$ No information for the studies Mexico 2, Mexico 3, Brazil $1^{13}$ and Brazil $2 .{ }^{12}$
}

Table 3. Pooled odds ratios (ORs) and $95 \%$ confidence intervals (Cls) for gastric cancer according to tertiles of meat consumption (grams per [g/] day).

[1]Pooled ORs were computed using random-effects models which included, when available and applicable, terms for sex, age (5-year age groups: $<40 ; 40-44 ; . . . ; 70-74 ; \geq 75)$, socioeconomic status (low, intermediate, or high, as defined in each original study based on education, income or occupation), smoking status (never, former and current smokers of $\leq 10$ cigarettes/day; 11 to 20 cigarettes/day; $>20$ cigarettes/day), alcohol drinking (never, low: $\leq 12 \mathrm{~g}$ of ethanol/day, intermediate: $>12$ to $47 \mathrm{~g}$ of ethanol/day, high: $>47 \mathrm{~g}$ of ethanol/day), fruits and vegetables consumption (studyspecific tertiles), total energy intake (study-specific quintiles), study center (for multicenter studies), and race/ethnicity ("White", "Black/African American", "Asian", "Hispanic/Latino", "Other") , family history of gastric cancer and body mass categories $\left(<18.5 ; 18.5-25 ; 25-30 ;>30 \mathrm{~kg} / \mathrm{m}^{2}\right)$.

${ }^{[2]}$ No information for the studies Italy $3^{21}$ and Japan $1 .{ }^{24}$

${ }^{[3]}$ No information for the study Japan $1 .{ }^{24}$

Table 4. Pooled odds ratios (ORs) and 95\% confidence intervals (Cls) of gastric cancer for the

highest compared to the lowest study-specific tertile of different sources of meat in strata of selected variables.

[1]Pooled ORs were computed using random-effects models, which included, when available and applicable, terms for sex, age (5-year age groups: $\langle 40 ; 40-44 ; . . . ; 70-74 ; \geq 75)$, socioeconomic status (low, intermediate, or high, as defined in each original study based on education, income or occupation), smoking status (never, former and current smokers of $\leq 10$ cigarettes/day; 11 to 20 cigarettes/day; >20 cigarettes/day), alcohol drinking (never, low: $\leq 12 \mathrm{~g}$ of ethanol/day, 
intermediate: $>12$ to $47 \mathrm{~g}$ of ethanol/day, high: $>47 \mathrm{~g}$ of ethanol/day), fruits and vegetables consumption (studyspecific tertiles), total energy intake (study-specific quintiles), study center (for multicenter studies), and race/ethnicity ("White", "Black/African American", "Asian", "Hispanic/Latino", "Other", family history of gastric cancer and body mass categories (<18.5; $\left.18.5-25 ; 25-30 ;>30 \mathrm{~kg} / \mathrm{m}^{2}\right)$.

[2] No information for the study Japan $2 .{ }^{23}$ As defined in each original study based on education, income or occupation.

${ }^{[3]}$ Includes studies Brazil 1, ${ }^{13}$ Brazil 2,12 Greece, ${ }^{17}$ Italy 1, ${ }^{19}$ Italy 2, ${ }^{20}$ Italy 3, ${ }^{21}$ Japan $1,{ }^{24}$ Japan 2, ${ }^{25}$ Japan 3, ${ }^{23}$ Mexico $3,{ }^{27}$ Russia $^{30}$ and Spain $2 .{ }^{32}$

${ }^{[4]}$ Includes studies Canada, ${ }^{14}$ China $2,{ }^{15}$ China 3, ${ }^{16}$ Iran $1,{ }^{18}$ Italy 4, ${ }^{22}$ Mexico $1,{ }^{26}$ Mexico $2,{ }^{28}$ Portugal ${ }^{29}$ and Spain $1 .{ }^{31}$ ${ }^{[5]}$ Excluding studies China $2,{ }^{15}$ China $3^{16}$ and Mexico 3.27

${ }^{[6]}$ Excluding studies China 2,15 Greece, ${ }^{17}$ Italy 1,19 Japan 2,25 Japan $3^{23}$ and Mexico 2. ${ }^{28}$

${ }^{[7]}$ No information for studies Canada, ${ }^{14}$ Russia, ${ }^{30}$ Iran 1, ${ }^{18}$ Japan 2, ${ }^{23}$ Brazil $1^{13}$ and Brazil $2 .{ }^{12}$

${ }^{[8]} \mathrm{H}$. pylori infection was defined using the same criteria of the original studies, according to the following serological tests: enzyme-linked immunosorbent assay (ELISA) tests (9 studies)12, 13, 18, 23, 24, 26, 27, 29, 30 to determine immunoglobulin $\mathrm{G}(\mathrm{IgG})$ antibody titers in serum, and in one study through multiplex serology. ${ }^{31}$ When anti-H. pylori serum IgG titers were assessed using an ELISA-based method, participants with borderline results were classified as testing positive for $H$. pylori infection. 
Figure 1. Study-specific and pooled odds ratio (ORs) and corresponding 95\% confidence intervals (Cl) of gastric cancer risk for the highest tertile of meat (white, red, processed and total meat) consumption compared to the lowest tertile.

NA - not available; OR - Odds ratio; $95 \% \mathrm{Cl}$ - 95\% confidence interval; USA - United States of America

Figure 2. Relation between red (A) and processed (B) meat (g/day) and risk of gastric cancer fitted by a fractional polynomial.

OR - odds ratio 
Table 1. Median and interquartile range (grams per [g/] day) of white, red and processed meat intake, by case-control status and study.

\begin{tabular}{|c|c|c|c|c|c|c|c|c|c|c|}
\hline & \multicolumn{5}{|c|}{ Cases $(n=11,443)$} & \multicolumn{5}{|c|}{ Controls $(n=28,029)$} \\
\hline & \multirow[t]{2}{*}{$\mathbf{N}$} & \multirow[t]{2}{*}{$\%$} & \multicolumn{3}{|c|}{$\begin{array}{c}\text { Median (P25-P75) } \\
\text { g/day }\end{array}$} & \multirow[t]{2}{*}{$\mathbf{N}$} & \multirow[t]{2}{*}{$\%$} & \multicolumn{3}{|c|}{$\begin{array}{c}\text { Median (P25-P75) } \\
\text { g/day }\end{array}$} \\
\hline & & & White & Red & Processed & & & White & Red & Processed \\
\hline \multicolumn{11}{|l|}{ Study center } \\
\hline rica & 2,324 & 20.3 & $\begin{array}{c}20.0 \\
(9.0-48.6)\end{array}$ & $\begin{array}{c}61.3 \\
(32.4-100.0)\end{array}$ & $\begin{array}{c}13.9 \\
(4.0-27.6)\end{array}$ & 7,261 & 25.9 & $\begin{array}{c}16.2 \\
(9.7-48.6)\end{array}$ & $\begin{array}{c}56.2 \\
(31.4-88.6)\end{array}$ & $\begin{array}{c}11.9 \\
(3.2-24.8)\end{array}$ \\
\hline zil $1^{13}$ & 226 & 2.0 & $\begin{array}{c}20.0 \\
(20.0-50.0)\end{array}$ & $\begin{array}{c}78.0 \\
(48.0-100.0)\end{array}$ & $\begin{array}{c}0.0 \\
(0.0-26.5)\end{array}$ & 226 & 0.8 & $\begin{array}{c}20.0 \\
(20.0-50.0)\end{array}$ & $\begin{array}{c}99.5 \\
(50.0-100.0)\end{array}$ & $\begin{array}{c}0.0 \\
(0.0-26.5)\end{array}$ \\
\hline $2^{12}$ & 93 & 0.8 & $\begin{array}{c}50.0 \\
(20.0-50.0)\end{array}$ & $\begin{array}{c}85.0 \\
(50.0-100.0)\end{array}$ & $\begin{array}{c}0.0 \\
(0.0-26.5)\end{array}$ & 186 & 0.7 & $\begin{array}{c}20.0 \\
(20.0-50.0)\end{array}$ & $\begin{array}{c}50.0 \\
(20.0-100.0)\end{array}$ & $\begin{array}{c}0.0 \\
(0.0-26.5)\end{array}$ \\
\hline $\mathrm{da}^{14}$ & 1,171 & 10.2 & $\begin{array}{c}16.2 \\
(16.2-48.6)\end{array}$ & $\begin{array}{c}71.4 \\
(40.0-104.8)\end{array}$ & $\begin{array}{c}19.1 \\
(8.9-33.7)\end{array}$ & 5,019 & 17.9 & $\begin{array}{c}16.2 \\
(16.2-48.6)\end{array}$ & $\begin{array}{c}63.8 \\
(39.0-97.2)\end{array}$ & $\begin{array}{c}14.7 \\
(4.7-26.6)\end{array}$ \\
\hline ico $1^{26}$ & 248 & 2.2 & $\begin{array}{c}26.9 \\
(9.0-26.9)\end{array}$ & $\begin{array}{c}38.6 \\
(21.8-64.7)\end{array}$ & $\begin{array}{c}7.6 \\
(2.8-15.1)\end{array}$ & 478 & 1.7 & $\begin{array}{c}26.9 \\
(9.0-26.9))\end{array}$ & $\begin{array}{c}30.3 \\
(14.5-54.9)\end{array}$ & $\begin{array}{c}6.6 \\
(2.3-12.7)\end{array}$ \\
\hline Mexico $2^{28}$ & 220 & 1.9 & $\begin{array}{c}29.1 \\
(29.1-29.1)\end{array}$ & $\begin{array}{c}48.6 \\
(32.2-81.4)\end{array}$ & $\begin{array}{c}14.9 \\
(6.9-28.2)\end{array}$ & 752 & 2.7 & $\begin{array}{c}29.1 \\
(9.7-29.1))\end{array}$ & $\begin{array}{c}43.4 \\
(26.5-71.2)\end{array}$ & $\begin{array}{c}12.4 \\
(4.1-24.4)\end{array}$ \\
\hline $\cos 3^{27}$ & 234 & 2.0 & $\begin{array}{c}8.9 \\
(4.5-26.8)\end{array}$ & $\begin{array}{c}42.4 \\
(16.8-77.5)\end{array}$ & $\begin{array}{c}6.4 \\
(2.3-12.9)\end{array}$ & 468 & 1.7 & $\begin{array}{c}8.9 \\
(4.5-26.8)\end{array}$ & $\begin{array}{c}36.7 \\
(12.1-71.3)\end{array}$ & $\begin{array}{c}5.8 \\
(2.1-10.0)\end{array}$ \\
\hline & 132 & 1.2 & $\begin{array}{c}1.4 \\
(0.0-6.7)\end{array}$ & $\begin{array}{c}42.2 \\
(21.2-83.9)\end{array}$ & $\begin{array}{c}15.7 \\
(4.5-31.9)\end{array}$ & 132 & 0.5 & $\begin{array}{c}0.3 \\
(0.0-3.3)\end{array}$ & $\begin{array}{c}25.8 \\
(7.1-50.3)\end{array}$ & $\begin{array}{c}6.1 \\
(1.3-18.3)\end{array}$ \\
\hline & 5,054 & 44.2 & $\begin{array}{c}10.5 \\
(3.5-10.5)\end{array}$ & $\begin{array}{c}26.6 \\
(12.6-38.9)\end{array}$ & $\begin{array}{c}1.8 \\
(0.0-5.3)\end{array}$ & 10,826 & 38.6 & $\begin{array}{c}10.5 \\
(3.5-10.5)\end{array}$ & $\begin{array}{c}26.6 \\
(12.6-37.8)\end{array}$ & $\begin{array}{c}1.7 \\
(0.0-5.3)\end{array}$ \\
\hline China $2^{15}$ & 182 & 1.6 & $\begin{array}{c}0.4 \\
(0.0-3.3)\end{array}$ & $\begin{array}{c}25 \\
(10.4-42.9)\end{array}$ & $\begin{array}{c}0.8 \\
(0.0-12.5)\end{array}$ & 403 & 1.4 & $\begin{array}{c}2.5 \\
(0.3-6.9)\end{array}$ & $\begin{array}{c}36.9 \\
(14.6-68.8)\end{array}$ & $\begin{array}{c}0.4 \\
(0.0-14.3)\end{array}$ \\
\hline & 692 & 6.1 & $\begin{array}{c}5.0 \\
(2.2-10.0)\end{array}$ & $\begin{array}{c}31.9 \\
(15.9-59.5)\end{array}$ & $\begin{array}{c}5.0 \\
(1.4-10.0)\end{array}$ & 686 & 2.5 & $\begin{array}{c}6.7 \\
(3.3-13.3)\end{array}$ & $\begin{array}{c}40.0 \\
(19.3-66.2)\end{array}$ & $\begin{array}{c}3.6 \\
(1.1-10.0)\end{array}$ \\
\hline & 216 & 1.9 & $\begin{array}{c}21.0 \\
(21.0-50.0)\end{array}$ & $\begin{array}{c}50 \\
(21.0-250.0)\end{array}$ & $\begin{array}{c}0.0 \\
(0.0-0.0)\end{array}$ & 393 & 1.4 & $\begin{array}{c}21.0 \\
(21.0-50.0)\end{array}$ & $\begin{array}{c}35.5 \\
(21.0-50.0)\end{array}$ & $\begin{array}{c}0.0 \\
(0.0-0.0)\end{array}$ \\
\hline $1^{24[1]}$ & 1,260 & 11.1 & & $\begin{array}{c}27.0 \\
(18.5-42.5)\end{array}$ & & 3,914 & 14,0 & & $\begin{array}{c}27.0 \\
(17.5-42.5)\end{array}$ & \\
\hline & 2,551 & 22.3 & $\begin{array}{c}10.5 \\
(3.5-10.5)\end{array}$ & $\begin{array}{c}26.6 \\
(12.6-37.8)\end{array}$ & $\begin{array}{c}1.8 \\
(0.0-5.3)\end{array}$ & 5,127 & 18.4 & $\begin{array}{c}10.5 \\
(3.5-10.5)\end{array}$ & $\begin{array}{c}26.6 \\
(12.6-37.8)\end{array}$ & $\begin{array}{c}1.8 \\
(0.0-5.3) 1\end{array}$ \\
\hline & 153 & 1.3 & $\begin{array}{c}6.7 \\
(2.3-14.7)\end{array}$ & $\begin{array}{c}41.7 \\
(28.3-61.2)\end{array}$ & $\begin{array}{c}4.3 \\
(1.5-10.3)\end{array}$ & 303 & 1.1 & $\begin{array}{c}7 \\
(2.3-15.0)\end{array}$ & $\begin{array}{c}45.8 \\
(25.8-71.4)\end{array}$ & $\begin{array}{c}5.2 \\
(2.0-11.2)\end{array}$ \\
\hline & 4,065 & 35.5 & $\begin{array}{c}25.7 \\
(14.3-42.9)\end{array}$ & $\begin{array}{c}49.1 \\
(28.1-66.8)\end{array}$ & $\begin{array}{c}21.4 \\
(10.7-38.3)\end{array}$ & 9,942 & 35.5 & $\begin{array}{c}21.6 \\
(14.3-35.2)\end{array}$ & $\begin{array}{c}38.1 \\
(21.4-58.7)\end{array}$ & $\begin{array}{c}21.4 \\
(10.7-34.6)\end{array}$ \\
\hline Treece ${ }^{17}$ & 110 & 1.0 & $\begin{array}{c}14.3 \\
(14.3-28.6)\end{array}$ & $\begin{array}{c}44.5 \\
(28.6-71.4)\end{array}$ & $\begin{array}{c}0.0 \\
(0.0-1.7)\end{array}$ & 100 & 0.4 & $\begin{array}{c}14.3 \\
(8.8-28.6)\end{array}$ & $\begin{array}{c}42.9 \\
(28.6-57.1)\end{array}$ & $\begin{array}{c}0.0 \\
(0.0-1.7)\end{array}$ \\
\hline & 769 & 6.7 & $\begin{array}{c}28.6 \\
(14.3-28.6)\end{array}$ & $\begin{array}{c}46.4 \\
(32.1-71.4)\end{array}$ & $\begin{array}{c}28.6 \\
(17.9-39.3)\end{array}$ & 2,081 & 7.4 & $\begin{array}{c}28.6 \\
(14.3-28.6)\end{array}$ & $\begin{array}{c}46.4 \\
(28.6-60.7)\end{array}$ & $\begin{array}{c}25.0 \\
(14.3-35.7)\end{array}$ \\
\hline $2^{20}$ & 230 & 1.2 & $\begin{array}{c}14.3 \\
(7.1-14.3)\end{array}$ & $\begin{array}{c}25 \\
(17.9-32.1)\end{array}$ & $\begin{array}{c}14.3 \\
(10.7-17.9)\end{array}$ & 547 & 2.0 & $\begin{array}{c}14.3 \\
(7.1-14.3)\end{array}$ & $\begin{array}{c}21.4 \\
(14.3-28.6)\end{array}$ & $\begin{array}{c}14.3 \\
(10.7-17.9)\end{array}$ \\
\hline y & 133 & 1.2 & NA & NA & $\begin{array}{c}23.8 \\
(12.2-41.6)\end{array}$ & 400 & 1.4 & NA & NA & $\begin{array}{c}21.4 \\
(21.4-57.1)\end{array}$ \\
\hline Italy $4^{22}$ & 1,016 & 8.9 & $\begin{array}{c}27.1 \\
(14.5-40)\end{array}$ & $\begin{array}{c}55.4 \\
(36.0-77.4)\end{array}$ & $\begin{array}{c}28.3 \\
(15.0-48.6)\end{array}$ & 1,159 & 4.1 & $\begin{array}{c}28.6 \\
(14.6-38.6)\end{array}$ & $\begin{array}{c}48.7 \\
(33.1-69.3)\end{array}$ & $\begin{array}{c}23.8 \\
(12.2-41.6)\end{array}$ \\
\hline Portugal ${ }^{29}$ & 633 & 5.5 & $\begin{array}{c}42.8 \\
(25.1-59.4)\end{array}$ & $\begin{array}{c}51.4 \\
(25.7-59.4)\end{array}$ & $\begin{array}{c}8.6 \\
(1.4-18.6)\end{array}$ & 1,600 & 5.7 & $\begin{array}{c}33.7 \\
(17.1-59.4)\end{array}$ & $\begin{array}{c}51.4 \\
(25.7-77.1)\end{array}$ & $\begin{array}{c}8.7 \\
(3.1-18.6)\end{array}$ \\
\hline Russia 30 & 446 & 3.9 & $\begin{array}{c}21.4 \\
(13.4-42.9)\end{array}$ & $\begin{array}{c}48.3 \\
(28.1-77.7)\end{array}$ & $\begin{array}{c}23.2 \\
(10.7-39.7)\end{array}$ & 607 & 2.2 & $\begin{array}{c}21.4 \\
(6.7-42.9)\end{array}$ & $\begin{array}{c}40.3 \\
(20.1-64.3)\end{array}$ & $\begin{array}{c}17.1 \\
(7.4-35.4)\end{array}$ \\
\hline Spain $1^{31}$ & 330 & 2.9 & $\begin{array}{c}20.7 \\
(14.5-30.5)\end{array}$ & $\begin{array}{c}32.0 \\
(20.5-50.6)\end{array}$ & $\begin{array}{c}32.6 \\
(20.5-55.6)\end{array}$ & 2,993 & 10.7 & $\begin{array}{c}18.9 \\
(12.7-26.6)\end{array}$ & $\begin{array}{c}26.5 \\
(15.5-42.9)\end{array}$ & $\begin{array}{c}26.9 \\
(15.5-42.1)\end{array}$ \\
\hline Spain $2^{32}$ & 398 & 3.5 & $\begin{array}{c}37.6 \\
(25.4-44.3)\end{array}$ & $\begin{array}{c}53.8 \\
(24.6-60.5) \\
\end{array}$ & $\begin{array}{c}24.8 \\
(15.8-31.8)\end{array}$ & 455 & 1.6 & $\begin{array}{c}38.7 \\
(32.2-44.3)\end{array}$ & $\begin{array}{c}53.8 \\
(24.2-60.5) \\
\end{array}$ & $\begin{array}{c}24.8 \\
(14.3-30.1)\end{array}$ \\
\hline
\end{tabular}

NA - not available; P25-P75 - percentile 25- percentile 75; USA - United States of America; ${ }^{[1]}$ Only total meat available. 
Table 2. Distribution of gastric cancer cases and controls according to sex, age and other selected covariates.

\begin{tabular}{|c|c|c|c|c|}
\hline & \multicolumn{2}{|c|}{ Cases } & \multicolumn{2}{|c|}{ Controls } \\
\hline & $\mathbf{N}$ & $\%$ & $\mathbf{N}$ & $\%$ \\
\hline \multicolumn{5}{|l|}{ Sex } \\
\hline Male & 7,448 & 65.1 & 16,650 & 59.4 \\
\hline Female & 3,995 & 34.9 & 11,379 & 40.6 \\
\hline \multicolumn{5}{|l|}{ Age } \\
\hline$<40$ & 496 & 4.3 & 2,113 & 7.5 \\
\hline $40-45$ & 479 & 4.2 & 1,679 & 6.0 \\
\hline $45-50$ & 781 & 6.8 & 2,254 & 8.0 \\
\hline $50-54$ & 1,128 & 9.9 & 2,969 & 10.6 \\
\hline $55-59$ & 1,538 & 13.4 & 3,552 & 12.7 \\
\hline $60-64$ & 1,803 & 15.8 & 4,289 & 15.3 \\
\hline $65-69$ & 2,028 & 17.7 & 4,525 & 16.1 \\
\hline $70-74$ & 1,824 & 15.9 & 3,779 & 13.5 \\
\hline$\geq 75$ & 1,366 & 12.0 & 2,869 & 10.2 \\
\hline \multicolumn{5}{|c|}{ Socioeconomic status ${ }^{[1]}$} \\
\hline Low & 4,486 & 50.4 & 8,433 & 36.8 \\
\hline Intermediate & 2,416 & 27.2 & 6,955 & 30.4 \\
\hline High & 1,156 & 13.0 & 5,099 & 22.3 \\
\hline Missing & 834 & 9.4 & 2,415 & 10.5 \\
\hline \multicolumn{5}{|c|}{ History of stomach cancer in first degree relatives ${ }^{[2]}$} \\
\hline No & 6,495 & 73.2 & 16,330 & 79.2 \\
\hline Yes & 1,376 & 15.5 & 1,982 & 9.6 \\
\hline Missing & 1,007 & 11.3 & 2,314 & 11.2 \\
\hline \multicolumn{5}{|c|}{ Vegetables and fruit intake ${ }^{[3]}$} \\
\hline Low & 3,840 & 33.6 & 8,515 & 30.4 \\
\hline Intermediate & 3,938 & 34.4 & 9,737 & 34.7 \\
\hline High & 3,647 & 31.8 & 9,484 & 33.8 \\
\hline Missing & 18 & 0.2 & 293 & 1.1 \\
\hline \multicolumn{5}{|c|}{ Total energy intake ${ }^{[4]}$} \\
\hline $1^{\text {st }}$ quintile & 1,120 & 17.2 & 3,123 & 19.8 \\
\hline $2^{\text {nd }}$ quintile & 1,172 & 18.4 & 3,133 & 19.9 \\
\hline $3^{\text {rd }}$ quintile & 1,228 & 18.8 & 3,135 & 19.9 \\
\hline $4^{\text {th }}$ quintile & 1,268 & 19.5 & 3,136 & 19.9 \\
\hline $5^{\text {th }}$ quintile & 1,501 & 23.1 & 3,137 & 19.9 \\
\hline Missing & 198 & 3.1 & 72 & 0.5 \\
\hline \multicolumn{5}{|c|}{ Body Mass Index $\left(\mathrm{kg} / \mathrm{m}^{2}\right)^{[5]}$} \\
\hline$<18.5$ & 533 & 4.9 & 826 & 3.1 \\
\hline $18.5-25$ & 5,605 & 51.3 & 13,360 & 49.4 \\
\hline $25-30$ & 2,707 & 24.8 & 7,693 & 28.5 \\
\hline$>30$ & 1,446 & 13.2 & 3,197 & 11.8 \\
\hline Missing & 639 & 5.9 & 1,953 & 7.2 \\
\hline
\end{tabular}




\section{Cigarette smoking}

\begin{tabular}{lcccc} 
Never & 4,670 & 40.9 & 12,787 & 45.7 \\
Former & 3,063 & 26.8 & 7,626 & 27.2 \\
Current (cigarettes/day) & & & & \\
$\quad \leq 10$ & 775 & 6.8 & 2,208 & 7.9 \\
$\quad 11-20$ & 1,607 & 14.1 & 3,164 & 11.3 \\
$\quad>20$ & 1,026 & 9.0 & 1,867 & 6.7 \\
Missing & 281 & 2.5 & 343 & 1.2 \\
cohol intake & & & & \\
Never & 3,810 & 37.8 & 10,803 & 43.5 \\
Low (<12 g of ethanol/day) & 2,423 & 24.1 & 5,283 & 21.3 \\
Intermediate (>12-47 g of ethanol/day) & 2,497 & 24.8 & 5,582 & 22.4 \\
High (>47 g of ethanol/day) & 1,036 & 10.3 & 2,035 & 8.2 \\
Missing & 302 & 3.0 & 1,145 & 4.6 \\
\hline
\end{tabular}

${ }^{1}$ No information for the study Japan $2 .{ }^{23}$ As defined in each original study based on education, income or occupation.

${ }^{2}$ No information for the studies Canada, ${ }^{14}$ China 3, ${ }^{16}$ Mexico $1,{ }^{26}$ Mexico $2^{28}$ and Mexico $3 .{ }^{27}$

${ }^{3}$ Defined according to study-specific tertiles.

${ }^{4}$ No information for the studies Canada, ${ }^{14}$ China 2, ${ }^{15}$ Russia, ${ }^{30}$ Iran 1, ${ }^{18}$ Japan 2,, ${ }^{23}$ Brazil $1^{13}$ and Brazil 2. ${ }^{12}$

${ }^{5}$ No information for the studies Mexico 2, Mexico 3, Brazil $1^{13}$ and Brazil $2 .{ }^{12}$ 
Table 4. Pooled odds ratios (ORs) and $95 \%$ confidence intervals (Cls) of gastric cancer for the highest compared to the lowest study-specific tertile of different sources of meat in strata of selected variables.

\begin{tabular}{|c|c|c|c|c|c|c|c|c|}
\hline & \multicolumn{2}{|c|}{ White Meat } & \multicolumn{2}{|l|}{ Red Meat } & \multicolumn{2}{|c|}{ Processed Meat } & \multicolumn{2}{|l|}{ Total Meat } \\
\hline & OR (95\% Cl) ${ }^{[1]}$ & $I^{2}(\%)$ & OR $(95 \% \mathrm{Cl})^{[1]}$ & $I^{2}(\%)$ & OR $(95 \% \mathrm{Cl})^{[1]}$ & $I^{2}(\%)$ & OR $(95 \% \mathrm{Cl})^{[1]}$ & $I^{2}(\%)$ \\
\hline Overall & $1.09(0.93-1.26)$ & 56.4 & $1.24(1.00-1.53)$ & 82.3 & $1.23(1.06-1.43)$ & 60.2 & $1.30(1.09-1.55)$ & 77.9 \\
\hline \multicolumn{9}{|l|}{ Sex } \\
\hline Men & $1.00(0.89-1.13)$ & 5.4 & $1.19(0.97-1.46)$ & 65.6 & $1.21(1.05-1.38)$ & 26.4 & $1.23(1.05-1.45)$ & 52.3 \\
\hline Women & $1.27(0.94-1.70)$ & 67.4 & $1.28(0.96-1.69)$ & 69.0 & $1.29(0.99-1.68)$ & 64.0 & $1.41(1.06-1.86)$ & 72.4 \\
\hline P for interaction & 0.146 & & 0.690 & & 0.656 & & 0.421 & \\
\hline \multicolumn{9}{|l|}{ Age (years) } \\
\hline$\leq 55$ & $1.04(0.86-1.27)$ & 14.5 & $1.05(0.78-1.42)$ & 62.6 & $1.39(1.18-1.63)$ & 2.1 & $1.10(0.90-1.35)$ & 35.0 \\
\hline$>55$ to $\leq 65$ & $1.19(0.93-1.54)$ & 42.2 & $1.26(0.95-1.66)$ & 60.6 & $1.19(0.93-1.53)$ & 46.0 & $1.44(1.10-1.88)$ & 61.0 \\
\hline$>65$ & $0.97(0.83-1.14)$ & 12.4 & $1.38(1.09-1.75)$ & 59.9 & $1.13(0.92-1.39)$ & 45.2 & $1.33(1.07-1.67)$ & 58.2 \\
\hline $\mathrm{P}$ for interaction & 0.389 & & 0.364 & & 0.265 & & 0.238 & \\
\hline \multicolumn{9}{|l|}{ Area } \\
\hline Europe & $1.15(0.88-1.52)$ & 72.2 & $1.27(0.91-1.78)$ & 81.4 & $1.28(1.02-1.60)$ & 55.3 & $1.42(1.06-1.89)$ & 72.1 \\
\hline Asia & $0.97(0.72-1.30)$ & 60.0 & $0.94(0.59-1.51)$ & 87.3 & $0.98(0.80-1.20)$ & 27.3 & $1.01(0.74-1.38)$ & 81.1 \\
\hline Americas & $1.07(0.86-1.33)$ & 0.0 & $1.49(1.01-2.20)$ & 76.7 & $1.45(1.14-1.84)$ & 42.4 & $1.51(1.09-2.08)$ & 66.6 \\
\hline$P$ for interaction & 0.700 & & 0.330 & & 0.038 & & 0.159 & \\
\hline \multicolumn{9}{|c|}{ Socioeconomic status ${ }^{[2]}$} \\
\hline Low & $1.19(0.91-1.57)$ & 61.1 & $1.33(1.04-1.70)$ & 61.5 & $1.25(1.00-1.55)$ & 47.4 & $1.33(1.09-1.63)$ & 47.6 \\
\hline Intermediate & $0.91(0.73-1.13)$ & 14.1 & $1.13(0.81-1.58)$ & 66.4 & $1.25(0.95-1.63)$ & 49.9 & $1.28(0.95-1.74)$ & 62.5 \\
\hline High & $1.10(0.79-1.53)$ & 0.0 & $0.99(0.57-1.71)$ & 62.4 & $1.34(0.96-1.86)$ & 15.8 & $1.20(0.80-1.82)$ & 51.6 \\
\hline$P$ for interaction & 0.280 & & 0.540 & & 0.934 & & 0.903 & \\
\hline
\end{tabular}




\begin{tabular}{|c|c|c|c|c|c|c|c|c|}
\hline \multicolumn{9}{|l|}{ Smoking status } \\
\hline Never & $1.24(0.97-1.59)$ & 63.2 & $1.29(0.99-1.69)$ & 72.4 & $1.18(0.93-1.49)$ & 60.1 & 1.33 (1.04-1.69) & 70.5 \\
\hline Former & $1.01(0.85-1.19)$ & 0.0 & $1.28(1.08-1.52)$ & 4.3 & $1.31(1.06-1.62)$ & 24.1 & $1.32(1.14-1.53)$ & 0.7 \\
\hline Current & $0.89(0.72-1.11)$ & 14.3 & $1.04(0.76-1.41)$ & 55.3 & $1.10(0.93-1.30)$ & 0.0 & $1.08(0.88-1.32)$ & 26.5 \\
\hline$P$ for interaction & 0.138 & & 0.458 & & 0.446 & & 0.238 & \\
\hline \multicolumn{9}{|l|}{ Alcohol drinking } \\
\hline Non-drinker & $1.17(0.97-1.46)$ & 33.4 & $1.31(0.97-1.75)$ & 72.2 & $1.24(1.02-1.50)$ & 32.3 & $1.34(1.05-1.73)$ & 66.6 \\
\hline \multicolumn{9}{|l|}{ Drinker } \\
\hline Low ( $\leq 12$ g/day) & $1.19(0.88-1.59)$ & 50.2 & $1.10(0.79-1.53)$ & 67.7 & $1.32(0.97-1.81)$ & 60.5 & $1.26(0.92-1.72)$ & 68.1 \\
\hline Intermediate (>12-47 g/day) & $0.90(0.70-1.15)$ & 15.3 & $1.23(0.98-1.53)$ & 13.4 & $0.98(0.75-1.28)$ & 32.0 & $1.20(1.02-1.39)$ & 0.0 \\
\hline High (>47 g/day) & $0.96(0.57-1.61)$ & 36.5 & $1.03(0.65-1.63)$ & 31.7 & $1.54(1.12-2.12)$ & 0.0 & $1.42(1.06-1.91)$ & 0.0 \\
\hline$P$ for interaction & 0.312 & & 0.792 & & 0.175 & & 0.642 & \\
\hline \multicolumn{9}{|l|}{ Controls } \\
\hline Hospital-based ${ }^{[3]}$ & $1.05(0.87-1.26)$ & 17.3 & $1.51(1.09-2.11)$ & 76.4 & $1.31(1.03-1.66)$ & 54.0 & $1.42(1.08-1.86)$ & 72.6 \\
\hline Population-based ${ }^{[4]}$ & $1.10(0.89-1.40)$ & 72.5 & $1.05(0.80-1.38)$ & 84.8 & $1.17(0.96-1.44)$ & 68.1 & $1.20(0.94-1.53)$ & 81.8 \\
\hline$P$ for interaction & 0.687 & & 0.096 & & 0.505 & & 0.372 & \\
\hline \multicolumn{9}{|l|}{ Site $\mathrm{e}^{[5]}$} \\
\hline Cardia & $1.30(0.96-1.75)$ & 15.8 & $1.61(0.99-2.63)$ & 69.0 & $1.34(0.97-1.84)$ & 29.3 & $1.76(1.15-2.70)$ & 59.5 \\
\hline Non-cardia & $1.11(0.95-1.30)$ & 53.8 & $1.28(1.03-1.59)$ & 78.7 & $1.24(1.03-1.49)$ & 68.3 & 1.34 (1.11-1.62) & 74.9 \\
\hline$P$ for interaction & 0.370 & & 0.406 & & 0.676 & & 0.255 & \\
\hline \multicolumn{9}{|l|}{ Histological type ${ }^{[6]}$} \\
\hline Intestinal & $1.19(0.91-1.55)$ & 48.9 & $1.67(1.04-2.66)$ & 81.9 & $1.17(0.84-1.65)$ & 66.2 & $1.50(1.06-2.13)$ & 73.8 \\
\hline Diffuse & $1.28(1.03-1.58)$ & 11.0 & $1.34(0.91-1.98)$ & 63.4 & $1.44(1.16-1.80)$ & 12.4 & $1.46(1.12-1.90)$ & 46.1 \\
\hline Undifferentiated & $1.33(0.84-2.09)$ & 55.3 & $1.56(0.85-2.87)$ & 69.6 & $1.23(0.87-1.74)$ & 50.7 & $1.57(0.98-2.53)$ & 61.7 \\
\hline$P$ for interaction & 0.883 & & 0.770 & & 0.532 & & 0.964 & \\
\hline
\end{tabular}




\begin{tabular}{|c|c|c|c|c|c|c|c|c|}
\hline \multicolumn{9}{|l|}{ Vegetables and fruits intake } \\
\hline Low & $1.04(0.83-1.30)$ & 17.4 & $1.02(0.79-1.33)$ & 49.9 & $1.33(1.04-1.71)$ & 43.6 & $1.12(0.90-1.38)$ & 39.1 \\
\hline Intermediate & $0.97(0.83-1.12)$ & 0.0 & $1.29(1.02-1.62)$ & 44.3 & $1.23(1.00-1.52)$ & 34.9 & $1.32(1.07-1.63)$ & 44.5 \\
\hline High & $1.23(0.99-1.53)$ & 40.3 & $1.23(0.89-1.71)$ & 75.8 & $1.16(0.92-1.45)$ & 50.5 & $1.38(1.02-1.88)$ & 75.0 \\
\hline$P$ for interaction & 0.188 & & 0.413 & & 0.711 & & 0.418 & \\
\hline \multicolumn{9}{|l|}{ Family history of $\mathbf{G} \mathbf{C}^{[7]}$} \\
\hline No & $1.12(0.91-1.37)$ & 62.0 & $1.36(1.01-1.85)$ & 85.2 & $1.11(0.90-1.36)$ & 60.7 & $1.31(1.04-1.67)$ & 79.2 \\
\hline Yes & $1.16(0.91-1.48)$ & 0.0 & $1.19(0.68-2.07)$ & 77.9 & $1.30(0.84-1.99)$ & 37.2 & $1.56(0.83-2.93)$ & 68.9 \\
\hline $\mathrm{P}$ for interaction & 0.824 & & 0.671 & & 0.518 & & 0.626 & \\
\hline \multicolumn{9}{|c|}{ Body Mass Index (BMI) $\left(\mathrm{kg} / \mathrm{m}^{2}\right)$} \\
\hline$<18.5$ & $0.56(0.14-2.27)$ & 60.9 & $1.76(0.66-4.73)$ & 43.7 & $0.94(0.25-3.56)$ & 55.2 & $0.97(0.62-1.53)$ & 0.7 \\
\hline $18.5-25$ & $1.00(0.86-1.15)$ & 5.7 & $1.24(1.01-1.52)$ & 43.0 & $1.15(0.89-1.50)$ & 64.1 & $1.29(1.01-1.66)$ & 70.2 \\
\hline $25-30$ & $1.03(0.75-1.42)$ & 59.0 & $1.15(0.84-1.58)$ & 61.7 & $1.46(1.18-1.81)$ & 22.8 & $1.28(1.01-1.63)$ & 42.3 \\
\hline$>30$ & $1.50(0.83-2.69)$ & 65.8 & $1.37(0.73-2.59)$ & 58.9 & $1.37(0.98-1.91)$ & 0.0 & $1.51(1.02-2.22)$ & 36.0 \\
\hline P for interaction & 0.485 & & 0.852 & & 0.530 & & 0.553 & \\
\hline \multicolumn{9}{|l|}{$\begin{array}{l}\text { Studies with information on } \\
\text { total energy intake } \mathrm{e}^{[7]}\end{array}$} \\
\hline Adjusting for energy & $1.02(0.82-1.26)$ & 63.0 & $1.06(0.84-1.33)$ & 68.9 & $1.16(1.00-1.35)$ & 35.9 & $1.22(1.06-1.41)$ & 35.7 \\
\hline Not-adjusting for energy & $1.06(0.86-1.31)$ & 64.4 & $1.22(0.95-1.56)$ & 77.8 & $1.31(1.10-1.56)$ & 54.9 & $1.36(1.13-1.63)$ & 64.3 \\
\hline \multicolumn{9}{|c|}{$\begin{array}{l}\text { Studies with information on } H \text {. } \\
\text { pylori (HP) infection }{ }^{[8]}\end{array}$} \\
\hline Adjusting for HP & $1.22(0.92-1.62)$ & 60.3 & $1.29(0.77-2.17)$ & 89.7 & $1.15(0.91-1.46)$ & 44.6 & $1.35(0.93-1.96)$ & 82.6 \\
\hline Not-adjusting for HP & $1.21(0.91-1.60)$ & 66.0 & $1.25(0.76-2.04)$ & 89.9 & $1.15(0.88-1.49)$ & 61.3 & $1.28(0.89-1.82)$ & 84.5 \\
\hline
\end{tabular}

This article is protected by copyright. All rights reserved. 
${ }^{[2]}$ No information for the study Japan $2 .{ }^{23}$ As defined in each original study based on education, income or occupation.

${ }^{[3]}$ Includes studies Brazil 1, ${ }^{13}$ Brazil 2, ${ }^{12}$ Greece, ${ }^{17}$ Italy $1,{ }^{19}$ Italy $2,{ }^{20}$ Italy $3,{ }^{21}$ Japan $1,{ }^{24}$ Japan $2,{ }^{25}$ Japan $3,,^{23}$ Mexico $3,{ }^{27}$ Russia ${ }^{30}$ and Spain $2 .{ }^{32}$

${ }^{[4]}$ Includes studies Canada, ${ }^{14}$ China $2,{ }^{15}$ China $3,{ }^{16}$ Iran $1,{ }^{18}$ Italy $4,{ }^{22}$ Mexico $1,{ }^{26}$ Mexico $2,{ }^{28}$ Portugal ${ }^{29}$ and Spain $1 .{ }^{31}$

[5] Excluding studies China $2,{ }^{15}$ China $3^{16}$ and Mexico $3 .{ }^{27}$

${ }^{[6]}$ Excluding studies China 2,15 Greece, ${ }^{17}$ Italy $1,{ }^{19}$ Japan 2, ${ }^{25}$ Japan $3^{23}$ and Mexico $2 .{ }^{28}$

[7] No information for studies Canada, ${ }^{14}$ Russia, ${ }^{30}$ Iran 1, ${ }^{18}$ Japan 2, ${ }^{23}$ Brazil $1^{13}$ and Brazil $2 .{ }^{12}$

${ }^{[8]} \mathrm{H}$. pylori infection was defined using the same criteria of the original studies, according to the following serological tests: enzyme-linked immunosorbent assay (ELISA) tests ( 9 studies) ${ }^{12,}$, 13, 18 , $23,24,26,27,29,30$ to determine immunoglobulin $\mathrm{G}(\mathrm{IgG})$ antibody titers in serum, and in one study through multiplex serology. ${ }^{31}$ When anti-H. pylori serum IgG titers were assessed using an ELISAbased method, participants with borderline results were classified as testing positive for $H$. pylori infection. 


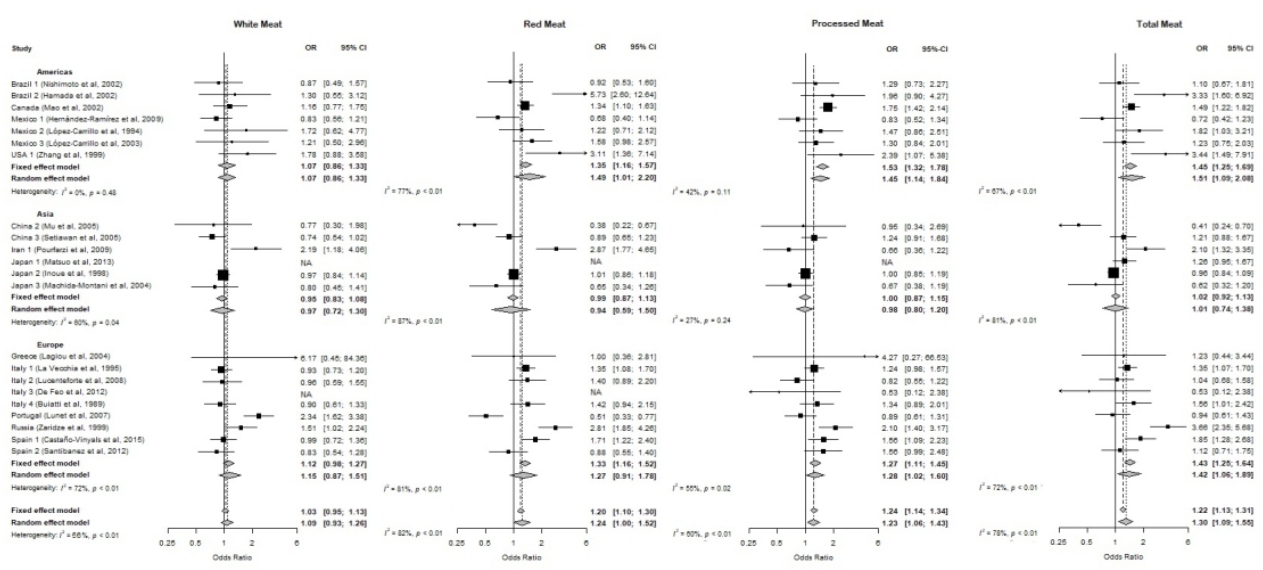


